\title{
A SÍNDROME DO "BURN-OUT": SOFRIMENTO PSIQUICO NOS PROFISSIONAIS DE SAÚDE ${ }^{\star}$

\author{
Hugo Leonardo Rodrigues Soares $\star \star$
} Carlos Eduardo Camargo Cunha $a^{\star \star}$
}

\section{Palavras-Chaves: Estafa Profissional. Síndrome do Burnout. Profissões da Saúde.}

Introdução: A síndrome da estafa profissional, também denominada síndrome do burnout, foi descrita pela primeira vez pelo psicólogo H.J. Freudenberger, no ano de 1974, para descrever um sentimento de fracasso e exaustão causado por um excessivo desgaste de energia, força e recursos. Maslasch foi uma das pioneiras nos estudos empíricos sobre a estafa profissional, sendo a autora do primeiro trabalho publicado sobre o tema em 1986. A síndrome da estafa constitui um quadro bem definido, caracterizado por exaustão emocional, despersonalização e redução da realização pessoal. A exaustão emocional representa o esgotamento dos recursos emocionais do indivíduo. É considerado o traço inicial da síndrome e decorre principalmente da sobrecarga e do conflito pessoal nas relações interpessoais. A despersonalização é caracterizada pela insensibilidade emocional do profissional, que passa a tratar clientes e colegas como objetos. Trata-se de um aspecto fundamental para caracterizar a síndrome de estafa (burnout), já que suas outras características podem ser encontradas nos quadros depressivos em geral. Por fim, a redução da realização pessoal (ou sentimento de incompetência) revela uma auto-avaliação negativa associada à insatisfação e infelicidade com o trabalho (Tucunduva et al, 2006). Os primeiros sentimentos negativos são direcionados aos desencadeantes do processo, ou seja, clientes e colegas de trabalho, posteriormente atingindo amigos e familiares e, por último, o próprio profissional. Sintomas físicos associados ao desgaste incluem cefaléia, alterações gastrointestinais e insônia, entre outros. As conseqüências da síndrome da estafa profissional podem ser graves, incluindo desmotivação, frustração, depressão e dependência de drogas. O desgaste se reflete também nas relações familiares (separações, maus tratos) e no trabalho, determinando diminuição importante do rendimento e aumento de absenteísmo. Objetivo: Abordar a questão da saúde mental dos profissionais de saúde levando-se em conta a estafa profissional gerada pela demanda do seu trabalho, cujas condições são adversas. Metodologia: Levantamento bibliográfico através de ampla revisão da literatura. Resultados e Conclusões: A estafa profissional pode ser observada em todas as profissões, principalmente naquelas que envolvem altos níveis de estresse, tais como controladores de tráfego aéreo, bombeiros e, particularmente, profissionais da área de saúde, como os médicos. Isto se deve tanto às características inerentes à profissão - como convívio intenso com pacientes,

\footnotetext{
* Trabalho apresentado na $29^{\text {a }}$ Semana Científica da Faculdade de Medicina, com menção honrosa.

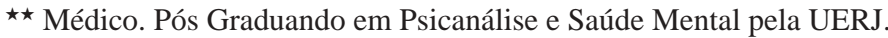

${ }^{\star \star \star}$ Médico Pneumologista do Emergência do Hospital Universitário Antônio Pedro.
} 
intensidade das interações emocionais e a falta de tempo livre para lazer e férias - quanto às mudanças pelas quais a prática médica vem passando nos últimos 20 anos, que incluem progressivo declínio da autonomia profissional, diminuição do status social da profissão e aumento das pressões sofridas por estes profissionais. Globalmente, a estafa profissional afeta um em cada dois médicos, sendo um terço deles afetado de forma importante e um décimo de forma severa, com características irreversíveis. Cerca de $40 \%$ a $50 \%$ dos médicos que trabalham com medicina de emergência e infectologia e intensivistas são acometidos (Tucunduva et al, 2006). Como medidas preventivas e de apoio sugerimos um serviço de atendimento psicológico/psiquiátrico aos profissionais de saúde; o desenvolvimento de atividades de lazer como a música e esportes; programas de humanização; melhoria nas condições de trabalho; criação de equipes multidisciplinares e a conscientização das vulnerabilidades e limitações. 